\title{
Platelet-Derived Growth Factor B Chain Is a Novel Target Gene of Cocaine-Mediated Notch1 Signaling: Implications for HIV-Associated Neurological Disorders
}

\author{
Honghong Yao, ${ }^{1 \star}$ Ming Duan, ${ }^{1,2 \star}$ Guoku Hu, ${ }^{1}$ and Shilpa Buch ${ }^{1}$ \\ ${ }^{1}$ Department of Pharmacology and Experimental Neuroscience, University of Nebraska Medical Center, Omaha, Nebraska 68198, and ${ }^{2}$ Key Laboratory of \\ Zoonosis, Jilin University, Changchun 130062, China
}

\begin{abstract}
Neuroinflammation associated with HIV-1 infection is exacerbated in cocaine-abusing, HIV + individuals. The underlying mechanisms are, in part, attributable to disruption of the blood-brain barrier modulated by cocaine via platelet-derived growth factor B chain (PDGF-B). Since Notch signaling plays a critical role in CNS homeostasis, we hypothesized that it may have a role in cocaine-mediated induction of PDGF-B. The goal of this study was to link Notch signaling with PDGF-B. Using Western blot analysis, we demonstrate the role of Notch1 signaling in cocaine-mediated induction of PDGF-B in human brain microvascular endothelial cells. Exposure of cells to the $\gamma$-secretase inhibitor-DAPT or silencing of Notch1 resulted in abrogation of cocaine-mediated induction of PDGF-B. Reciprocally, activation of the Notch1 receptor by exposing cells to the Notch ligand Jagged-1 resulted in upregulation of PDGF-B expression. Furthermore, it was demonstrated that cocaine-mediated activation of Notch1 signaling leading to targeted expression of PDGF-B involved activation of the downstream effector CSL. Functional implication of Notch1 signaling in regulating expression of the vascular permeant PDGF-B was confirmed in vitro using cell permeability assays. In vivo relevance was further corroborated in cocaine-treated mice that demonstrated increased permeability of the endothelial barrier as evidenced by Evans blue and sodium fluorescein extravasation. Specificity of Notch1 signaling in vivo was validated in mice exposed to DAPT, which failed to demonstrate barrier disruption following cocaine exposure. This is the first evidence of involvement of Notch1 activation in cocaine-mediated regulation of PDGF-B expression.
\end{abstract}

\section{Introduction}

Although the advent of combined anti-retroviral therapy has significantly decreased the incidence of HIV-associated neurological disorders (HAND), prevalence of the disease is actually on the rise (Sacktor et al., 2002; Antinori et al., 2007). Drug abuse has been implicated as a contributing risk factor for increased bloodbrain barrier (BBB) disruption and the ensuing neuroinflammation associated with HIV-1 infection (Webber et al., 1999; Nair et al., 2004). BBB is critical for the maintenance of CNS homeostasis and for the regulation of neuronal microenvironment. Intriguingly, cocaine use has been shown to open up the BBB (Fiala et al., 1998, 2005; Zhang et al., 1998). The mechanisms underlying the ability of cocaine to induce BBB damage however, remain elusive.

\footnotetext{
Received May 10, 2011; revised June 22, 2011; accepted July 12, 2011.

Author contributions: H.Y. and S.B. designed research; H.Y., M.D., and G.H. performed research; H.Y. and S.B. wrote the paper.

This work was supported by Grants MH-068212, DA020392, DA023397, and DA024442 (S.B.) and DA030285 (H.Y.) from the National Institutes of Health. We thank Yaman Lu for her technical support. We thank Dr. Aly Karsan (University of British Columbia, Vancouver, BC, Canada) for providing Flag-tagged CSL-VP16 and LNCX retroviral vectors for overexpression of CSL.

*H.Y. and M.D. contributed equally to this work.

The authors declare no competing financial interests.

Correspondence should be addressed to Dr. Shilpa J. Buch, Department of Pharmacology and Experimental Neuroscience, 985880 Nebraska Medical Center (DRC 8011), University of Nebraska Medical Center, Omaha, NE 68198-5880.E-mail: sbuch@unmc.edu.

DOI:10.1523/JNEUROSCI.2330-11.2011

Copyright $\odot 2011$ the authors $\quad 0270-6474 / 11 / 3112449-06 \$ 15.00 / 0$
}

Previous reports have indicated that PDGF signaling is critical for vascular development and for blood vessel homeostasis (Jin et al., 2008). More recently, intriguing findings by Su et al. (2008) have identified PDGF released from astrocytes as a key mediator of disruption of cerebrovascular permeability leading to increased risk for stroke. Consistent with this finding, we have also recently demonstrated PDGF-B as a regulator of cocaine-mediated BBB damage both in vitro and in vivo (Yao et al., 2011a), thereby underpinning the role of this factor in orchestrating BBB permeability.

Notch signaling has emerged as an important regulator of neuronal homeostasis. Similar to the physiological effects of PDGF, Notch signaling also mediates intercellular signals that affect proliferation, survival, and differentiation of endothelial cells (MacKenzie et al., 2004; Noseda et al., 2004). Notch receptors (Notch1 to 4 ) are transmembrane proteins, binding of ligands such as Delta and Jagged-1 resulting in proteolytic cleavage of the Notch receptors by the $\gamma$-secretase enzyme complex, leading to the release of a Notch intracellular domain (NICD). NICD subsequently translocates to the nucleus, where it interacts with the DNA binding factor CSL (also known as RBP-Jk and CBF1), ultimately culminating into transactivation of various promoters, such as those for the HES and HEY families. Additional immediate downstream genes of Notch signaling have also been characterized, suggesting the existence of a larger immediate Notch transcriptome. As an example, PDGF- $\beta$ R has been shown to be a target of Notch signaling gene in vascular smooth muscle 
cells (Jin et al., 2008). Whether Notch signaling is also involved in induction of the ligand PDGF-B, however, remains elusive. In this report, we demonstrate that Notch1 signaling is upstream of PDGF-B transcription in human brain microvascular endothelial cells (HBMECs) and identify it as a new member of the immediate Notch downstream target gene that plays a crucial role in $\mathrm{BBB}$ integrity.

\section{Materials and Methods}

Animals. C57BL/6N mice were purchased from Charles River Laboratories. All the animals were housed under conditions of constant temperature and humidity on a $12 \mathrm{~h}$ light, $12 \mathrm{~h}$ dark cycle, with lights on at 7:00 A.M. Food and water were available ad libitum. Animals were deeply anesthetized by overdose of isoflurane followed by pneumothorax before perfusion. All animal procedures were performed according to the protocols approved by the Institutional Animal Care and Use Committee of the University of Nebraska Medical Center.

Reagents. Cocaine, $\gamma$-secretase inhibitor DAPT ( $N$-[ $N$-(3,5-difluorophenacetyl)-L-alanyl]-S-phenylglycine $t$-butyl ester), and anti-Flag antibody were purchased from Sigma-Aldrich. Jagged-1 was obtained from ANASPEC. Flag-tagged CSL-VP16 and LNCX retroviral vectors for the overexpression of CSL were obtained from Dr. Aly Karsan (University of British Columbia, Vancouver, BC, Canada).

Cell culture. Primary HBMECs obtained from Dr. Monique Stins (Johns Hopkins University, Baltimore, MD) were cultured as described previously (Yao et al., 2011b). HBMECs were pretreated with pharmacological inhibitor (DAPT: $10 \mu \mathrm{mol} / \mathrm{L}$ or $50 \mu \mathrm{mol} / \mathrm{L}$ ) and Notch ligand (Jagged-1: $1 \mu \mathrm{mol} / \mathrm{L}$ or $10 \mu \mathrm{mol} / \mathrm{L})$ for $1 \mathrm{~h}$ followed by cocaine $(1,10$, or $100 \mu \mathrm{mol} / \mathrm{L}$ ) exposure.

Reverse transcription and real-time PCR. Reverse transcription (RT) and real-time PCR assays were performed as described previously (Yao et al., 2009, 2010). The primers for human CSL (GenBank accession number NM 005349) were as follows: upstream primer, 5 ' -CAGGCCACTCCATGTCCAA-3'; and downstream primer, 5'-ACCACAGGCACAGGAGTGACT-3'. The real-time PCR primer sequences for Hes1 and Hes5 were designed according to the previously published report (Kolev et al., 2008).

Western blotting. Treated cells were lysed using the Mammalian Cell Lysis kit (Sigma) as described earlier (Yao et al., 2009). The primary antibodies used were as follows: cleaved Notch1 (1:200, Cell Signaling Technology), PDGF-B (1:1000, Santa Cruz Biotechnology), and $\beta$-actin (1:4000, Sigma).

Short interfering RNA transfection. HBMEC cells were transfected with $20 \mathrm{nmol} / \mathrm{L}$ short interfering RNA (siRNA) for Notch1 and CSL from Dharmacon. The knockdown efficiency of siRNA Notch 1 and CSL was determined $2 \mathrm{~d}$ after transfection by Western blotting (WB) and RT-PCR analyses, respectively.

Chromatin immunoprecipitation assay. Chromatin immunoprecipitation assay was performed according to the manufacturer's instructions (Millipore). Briefly, HBMECs transfected with Flag-tagged CSL construct were treated with cocaine for $3 \mathrm{~h}$ and used for these assays as described previously (Yao et al., 2010, 2011a,b). Purified DNA was amplified via PCR to identify the promoter region containing the CSL binding site "TGGGAA." The sequence of the primers used to identify the PDGF-B promoter bound by CSL was as follows: sense: $5^{\prime}-$ CTGTGTGAAGGCTGGTTGTG-3', antisense: 5' -CCGAGTCTCCTCCTCCTAGC-3'.

Cell permeability. Primary HBMECs seeded on $6.5 \mathrm{~mm}$ polyester Transwell inserts $(0.4 \mu \mathrm{m}$ pore size $)$ were grown to confluence. Following confluency monolayers were exposed to cocaine $(10 \mu \mathrm{mol} / \mathrm{L})$, Jagged-1 (1 or $10 \mu \mathrm{mol} / \mathrm{L})$, DAPT $(10 \mu \mathrm{mol} / \mathrm{L})$, neutralizing PDGF-B antibody $(500 \mathrm{ng} / \mathrm{ml})$, or an isotype antibody, and the cell permeability was assessed as described earlier (Yao et al., 2011a).

Assessment of the BBB integrity. Assay of $\mathrm{BBB}$ integrity was performed in C57BL/6 mice. Mice were divided into four groups $(n=6)$ : (1) Saline, (2) Cocaine, (3) Cocaine plus DAPT, and (4) Cocaine plus DMSO. Cocaine was injected daily at a dose of $20 \mathrm{mg} / \mathrm{kg}$ (i.p.) for $7 \mathrm{~d}$. For the DAPT study, mice were injected with cocaine for $7 \mathrm{~d}$ and additionally on days 1 ,
A

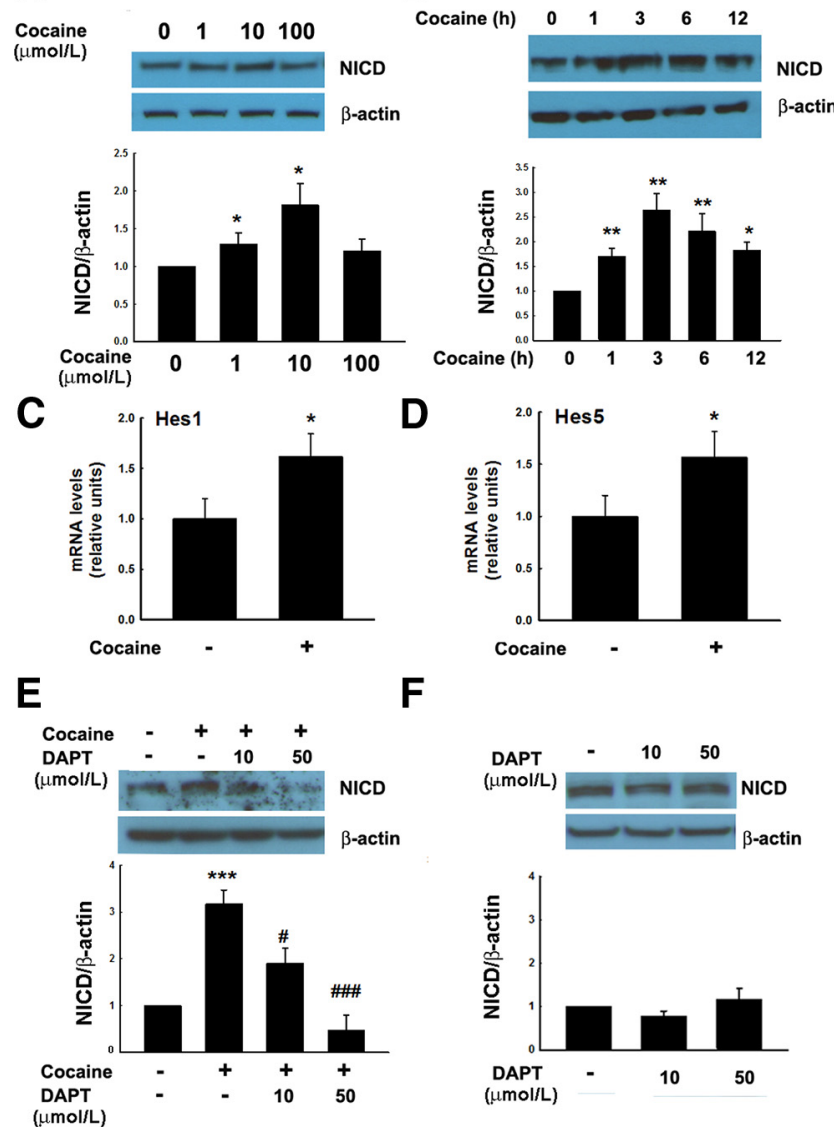

Figure 1. Cocaine-mediated increase of NICD levels in HBMECs. $A$, Effect of cocaine $(1,10$, and $100 \mu \mathrm{mol} / \mathrm{L}$ ) on NICD level in HBMECs. Whole-cell lysates from cocaine exposed cells $(3 \mathrm{~h})$ were subjected to WB using NICD antibody. $B$, Cocaine $(10 \mu \mathrm{mol} / \mathrm{L})$ induced time-dependent induction of NICD in HBMECs at the indicated time-points. C, D, HBMECs were treated with 10 $\mu \mathrm{mol} / \mathrm{L}$ cocaine for $3 \mathrm{~h}$ and the isolated total RNA was assessed for Hes $1(\boldsymbol{C})$ and Hes 5 (D) mRNA by real-time PCR analysis. $E$, DAPT is critical for cocaine-induced increase of NICD levels. Pretreatment of HBMECS with DAPT ( 10 or $50 \mu \mathrm{mol} / \mathrm{L}$ ) for $1 \mathrm{~h}$ followed by cocaine exposure $(3 \mathrm{~h}$ ) significantly inhibited cocaine-induced increase of NICD levels. $\boldsymbol{F}$, Immunoblots showing basal of level NICD in HBMECs treated with DAPT ( 10 or $50 \mu \mathrm{mol} / \mathrm{L}$ ) for $3 \mathrm{~h}$. Representative immunoblots and the densitometric analyses of $\mathrm{NICD} / \beta$-actin from four individual experiments are presented. All data are presented as mean $\pm S D$. ${ }^{*} p<0.05,{ }^{* *} p<0.01$, ${ }^{* * *} p<0.001$ versus control group; $" p<0.05$, ${ }^{\# \#} p<0.001$ versus cocaine-treated group.

3 , and 5 of cocaine injection, either DAPT or vehicle control DMSO (40 $\mathrm{mg} / \mathrm{kg}$, i.p; same volume of DMSO) was also administered. The dose of DAPT chosen was based on previous report (Arumugam et al., 2006). One day after the last cocaine injection (eighth day), animals were injected in the tail vein with $200 \mu$ l of sodium fluorescein $(6 \mathrm{mg} / \mathrm{ml}$; Sigma $)$ and evaluated for BBB permeability as previously described (Chen et al., 2009; Yao et al., 2011a). To further validate BBB permeability, another tracer such as Evans blue dye $(2 \%, 4 \mathrm{ml} / \mathrm{kg})$ was administered through the tail vein as described previously (Arumugam et al., 2006; Daneman et al., 2010).

Statistical analysis. Statistical analysis was performed using one-way ANOVA with a post hoc Student's $t$ test. Results were judged statistically significant if $p<0.05$ by ANOVA.

\section{Results}

\section{Cocaine-mediated activation of NICD in HBMECs}

Since Notch is known to play a critical role in blood vessel disorders (MacKenzie et al., 2004; Noseda et al., 2004) and cocaine is known to increase the permeability of blood vessels (Yao et al., 2011a), we reasoned that exposure of HBMECs to cocaine could involve activation of Notch1 signaling. Activation of Notch sig- 
A

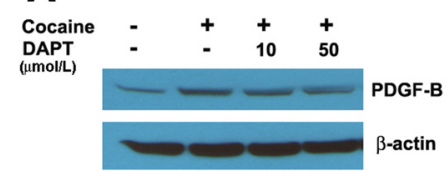

C

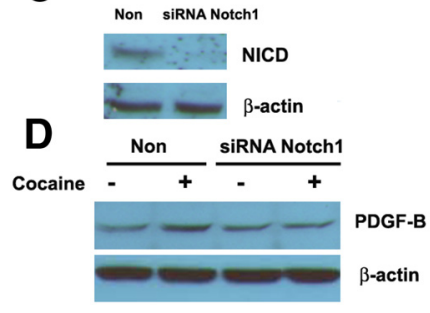

$\mathbf{F}$

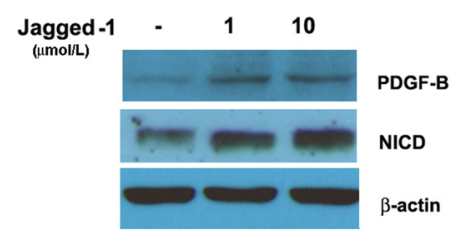

B

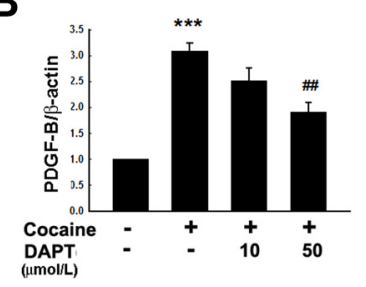

E

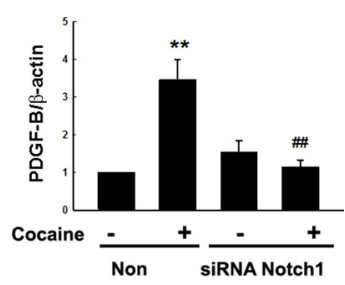

G

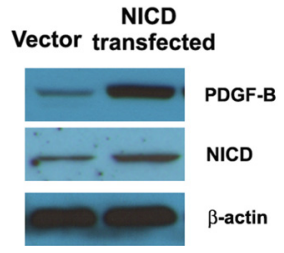

Figure 2. PDGF-B is a novel Notch1 immediate downstream target gene. $\boldsymbol{A}, \boldsymbol{B}$, Cocainemediated induction of PDGF-B was significantly attenuated in presence of DAPT ( $50 \mu \mathrm{mol} / \mathrm{L}$ ). $C$, Whole-cell lysates from HBMECs transfected with either Notch1/nonsense (Non) siRNAs were subject to WB. D, E, Notch1 siRNA but not Non siRNA inhibited cocaine-mediated induction of PDGF-B. HBMECs transfected with either Notch1 or Non siRNAs were treated with cocaine (10 $\mu \mathrm{mol} / \mathrm{L}$ ) for $12 \mathrm{~h}$ and assessed for PDGF-B expression. $F$, Treatment of cells with Jagged- 1 (1 or $10 \mu \mathrm{mol} / \mathrm{L}$ ) for $12 \mathrm{~h}$ induced PDGF-B expression. G, HBMECs were transfected with either an empty plasmid or a plasmid vector encoding NICD for $24 \mathrm{~h}$ and assessed for PDGF-B expression. Representative immunoblots and the densitometric analyses of PDGF-B/ $\beta$-actin from four individual experiments are presented. All data are presented as mean $\pm \mathrm{SD} .{ }^{* *} p<0.01,{ }^{* * *} p<$ 0.001 versus control group; ${ }^{\# \#} p<0.01$ versus cocaine-treated group.

naling involves cleavage of NICD by the $\gamma$-secretase complex (Noseda et al., 2006). As an initial screen to identify optimal concentration of cocaine that induced increased expression of cleaved Notch1 (NICD), HBMECs were first treated with varying concentrations of cocaine $(1,10$, and $100 \mu \mathrm{mol} / \mathrm{L})$ for $3 \mathrm{~h}$ and then assessed for induction of NICD by WB. As regards the physiological relevance of cocaine concentrations used in our study, it has been shown in humans that plasma cocaine concentrations following intranasal administration of cocaine often range between 0.4 and $1.6 \mu \mathrm{mol} / \mathrm{L}$ (Van Dyke et al., 1976), while plasma cocaine concentrations in tolerant abusers reach levels of 13 $\mu \mathrm{mol} / \mathrm{L}$ (Stephens et al., 2004). Additionally, cocaine concentrations up to $100 \mu \mathrm{mol} / \mathrm{L}$ and higher have been reported in postmortem brains of chronic human cocaine users following acute intoxication (Kalasinsky et al., 2000). We thus reasoned that cocaine concentrations ranging from 1 to $100 \mu \mathrm{mol} / \mathrm{L}$ would be compatible to the levels observed in humans.

As shown in Figure $1 A$, there was maximal induction of NICD at a concentration of $10 \mu \mathrm{mol} / \mathrm{L}$ with slightly lower levels in cells exposed to $100 \mu \mathrm{mol} / \mathrm{L}$ cocaine. The next step was to determine the time course of cocaine-mediated induction of NICD. As shown in Figure $1 B$, exposure of HBMECs to cocaine for varying times resulted in time-dependent induction of NICD with a maximal response at $3 \mathrm{~h}$, followed by a gradual decline thereafter (Fig. $1 \mathrm{~B})$. As a control for Notch signaling pathway, the canonical Notch target signature genes Hes 1 and Hes5 were also examined

A
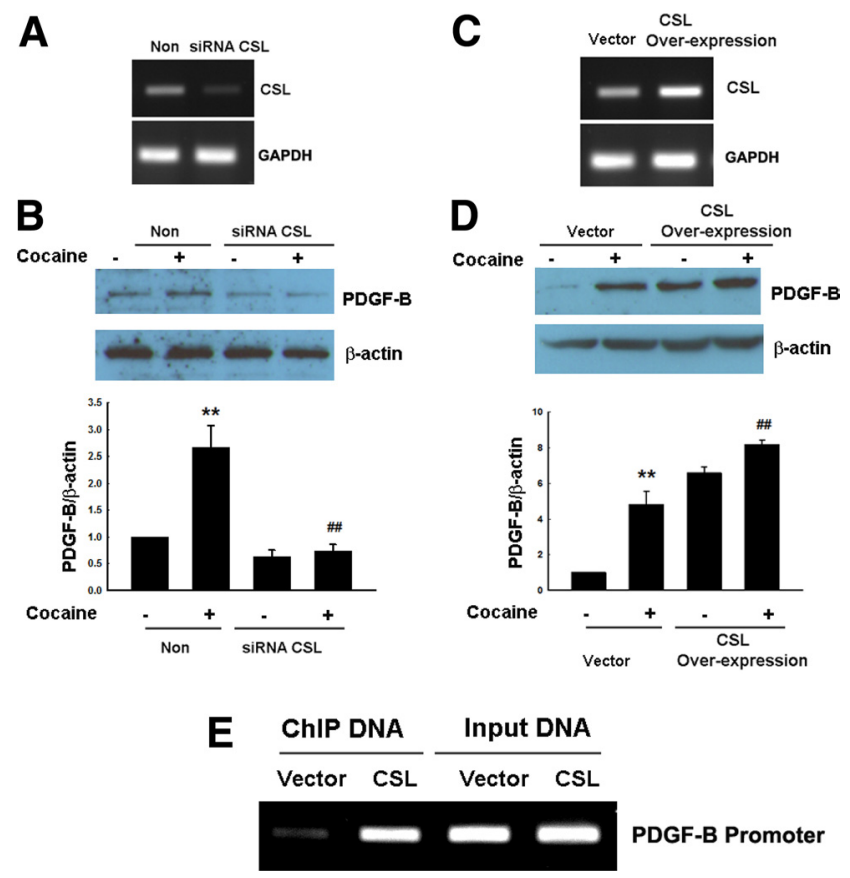

Figure 3. CSL activation is necessary for cocaine-mediated induction of PDGF- B gene. $A$, RNA extracted from HBMECs transfected with either CSL/Non siRNAs were subject to RT-PCR analysis. $\boldsymbol{B}$, CSL siRNA but not Non siRNA inhibited cocaine-mediated induction of PDGF-B. HBMECs were transfected with either CSL or Non siRNAs followed by treatment with cocaine (10 $\mu \mathrm{mol} / \mathrm{L})$ for $12 \mathrm{~h}$ and assessed for PDGF-B expression. C, Transfection of cells with plasmid encoding CSL resulted in overexpression of CSL. D, CSL overexpression increased PDGF-B expression, and this was enhanced by cocaine $(10 \mu \mathrm{mol} / \mathrm{L})$ treatment for $12 \mathrm{~h}$. E, CHIP assay in HBMECs expressing Flag-tagged CSL or vector control. PCR with primers flanking the CSL consensus sequence in the PDGF-B promoter was performed following immunoprecipitation with the Flag antibody. Representative immunoblots and the densitometric analyses of PDGF-B/ $\beta$-actin from four individual experiments are presented. All data are presented as mean $\pm S D .{ }^{* *} p<$ 0.01 versus control group; ${ }^{\#} p<0.01$ versus cocaine-treated group.

for increased transcription. As expected, HBMECs treated with cocaine $(10 \mu \mathrm{mol} / \mathrm{L})$ for $3 \mathrm{~h}$ demonstrated a significant increase in Hes1 and Hes5 mRNA levels (Fig. $1 C, D$ ). Since activation of immediate Notch downstream target genes requires $\gamma$-secretasemediated cleavage of NICD from the membrane, we next assessed the effect of $\gamma$-secretase inhibitor-DAPT on cocainemediated activation of Notch 1. HBMECs were pretreated with either 10 or $50 \mu \mathrm{mol} / \mathrm{L}$ DAPT for $1 \mathrm{~h}$ followed by exposure to 10 $\mu \mathrm{mol} / \mathrm{L}$ cocaine for $3 \mathrm{~h}$. As shown in Figure $1 \mathrm{E}$, DAPT significantly suppressed cocaine-mediated upregulation of NICD, thereby underscoring the role of Notch1 signaling in HBMECs exposed to cocaine. DAPT alone failed to alter the basal levels of NICD expression (Fig. $1 F$ ).

\section{PDGF-B is a novel Notch1 immediate downstream} target gene

It is well documented that members of the PDGF family play critical roles as cerebrovascular permeants, especially in $\mathrm{BBB}$ damage (Su et al., 2008). Furthermore, in our recent findings we have demonstrated that cocaine impaired endothelial integrity through PDGF-B (Yao et al., 2011a). To explore the relationship between cocaine-mediated activation of Notch 1 signaling and induction of PDGF-B expression, HBMECs were pretreated with DAPT and assessed for PDGF-B expression following $12 \mathrm{~h}$ treatment with cocaine. The concentrations used for cocaine exposure and the time point for PDGF-B expression were based on previous report (Yao et al., 2011a). HBMECs were pretreated with 
either 10 or $50 \mu \mathrm{mol} / \mathrm{L}$ DAPT for $1 \mathrm{~h}$ followed by cocaine $(10 \mu \mathrm{mol} / \mathrm{L})$ exposure for $12 \mathrm{~h}$. DAPT ( $50 \mu \mathrm{mol} / \mathrm{L}$ ) significantly ameliorated cocaine-mediated PDGF-B expression (Fig. 2A,B), thus underpinning the role of Notch1 in this process. Next, we wanted to validate the role of Notch1 signaling in cocaine-mediated induction of PDGF-B gene using the gene silencing approach by transfecting HBMECs with siRNA Notch1. Transfection of HBMECs with Notch1 siRNA resulted in efficient knockdown of Notch1 protein (Fig. 2C). Intriguingly, Notch1 siRNA but not the nonsense (Non) siRNA significantly abrogated cocaine-mediated upregulation of PDGF-B expression (Fig. 2D,E).

To further confirm the role of Notch 1 signaling in induction of PDGF-B, an alternative approach such as treating HBMECs with a known Notch1 ligand (Jagged-1 peptide) was used. As shown in Figure $2 F$, Jagged-1-mediated activation of Notch1 was capable of inducing NICD as expected, and also PDGF-B in HBMECs. Reciprocally, overexpressing NICD in HBMECs by transfecting cells with the NICD construct also led to upregulation of PDGF-B (Fig. $2 G$ ), thereby leading to the suggestion that PDGF-B gene was a downstream target of Notch1 in HBMECs.

\section{CSL activation is necessary for} cocaine-mediated induction of PDGF-B Based on the fact that NICD interacts with CSL to initiate gene transcription, and since human PDGF-B promoter contains a CSL consensus-binding site (TGGGAA), we enquired whether CSL activation was sufficient to induce PDGF-B expression. To achieve this, HBMECs were transfected with either a siRNA-CSL or a CSL overexpression construct and exposed to cocaine, following which PDGF-B chain expression was monitored $12 \mathrm{~h}$ after treatment. Knockdown of CSL was confirmed by RTPCR (Fig. 3A). Intriguingly, cocaine failed to increase PDGF-B expression in cells transfected with CSL siRNA compared with cells transfected with a Non siRNA (Fig. $3 B$ ). Validation of the role of CSL in Notch1-mediated expression of PDGF-B was also confirmed in cells overexpressing the CSL construct. In these cells, as expected, there was increased expression of PDGF-B, which was enhanced in the presence of cocaine at $12 \mathrm{~h}$ (Fig. 3C,D).

The next step was to confirm the binding of CSL to the PDGF-B promoter. For this, chromatin immunoprecipitation assay was performed in HBMECs transduced with vector encoding Flag-tagged
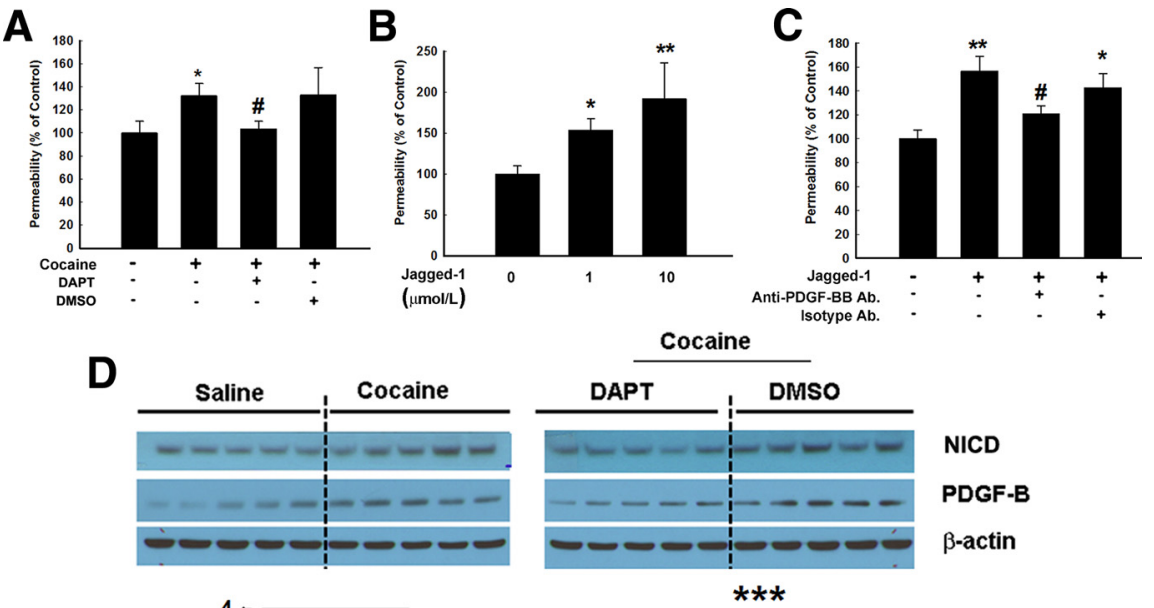

NICD PDGF-B

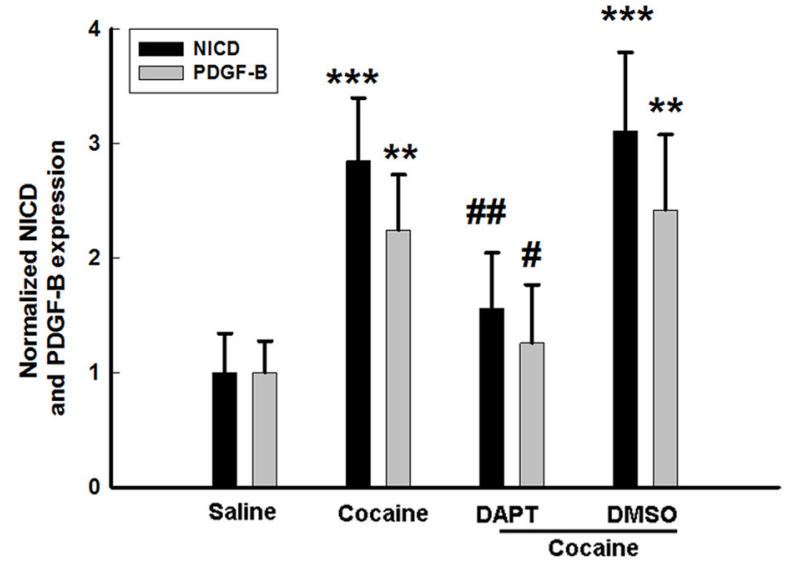

$\beta$-actin
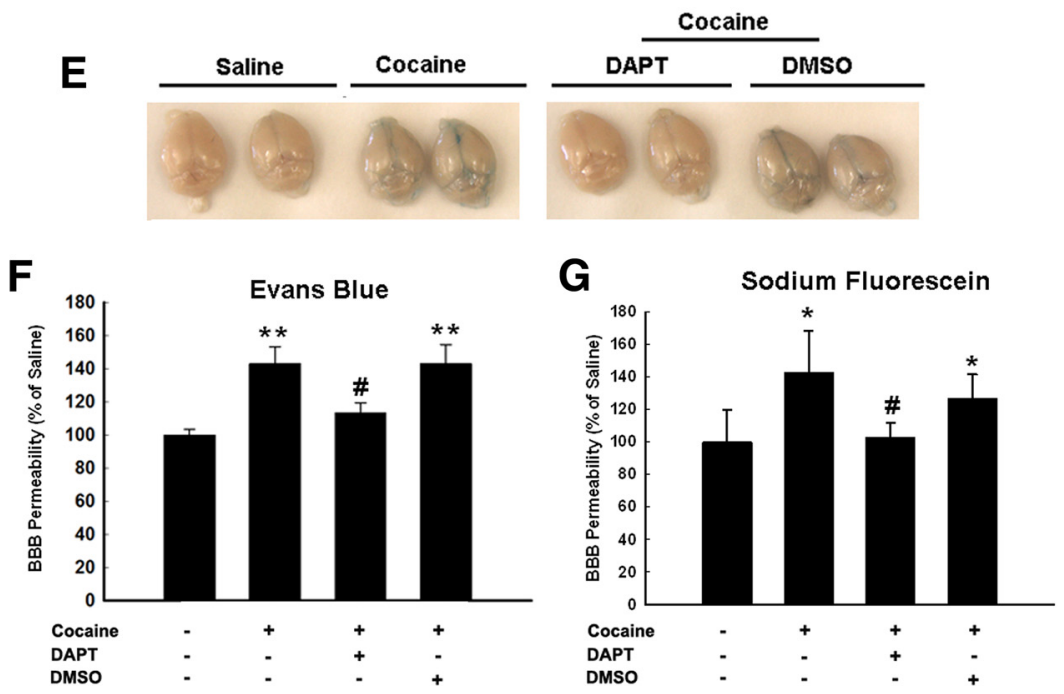

Figure 4. Notch1 signaling is critical for cocaine-mediated disruption of $B B B$. $A$, Cocaine-mediated increase in $B B B$ permeability was ameliorated in HBMECs pretreated with DAPT (50 $\mu \mathrm{mol} / \mathrm{L})$. B, Jagged-1 (1 or $10 \mu \mathrm{mol} / \mathrm{L})$ increased BBB permeability. C, Pretreatment of HBMECs with the PDGF-B-neutralizing antibody ameliorated Jagged-1 (10 $\mu \mathrm{mol} / \mathrm{L})$ induced BBB permeability. All the data are presented as mean $\pm S D$ of four individual experiments. ${ }^{*} p<0.05,{ }^{* *} p<0.01$ versus control group; ${ }^{*} p<0.05$ versus cocaine-treated group. $\boldsymbol{D}$, Cocaine administration in mice resulted in increased expression of NICD and PDGF-B, which was ameliorated by pretreatment with DAPT, but not with DMSO. Representative immunoblots and the densitometric analyses of NICD/ $\beta$-actin and PDGF-B/ $\beta$-actin from five animals per group are presented. ${ }^{* *} p<0.01 ;{ }^{* * *} p<0.001$ versus control group; ${ }^{\#} p<0.05 ;{ }^{\# \#} p<0.01$ versus cocaine-treated group. $E$, Dissected brains from saline, cocaine, cocaine +DAPT, and cocaine + DMSO groups of animals that were injected IV with Evans blue dye. Note the uniform bluish color in the brains of cocaine and cocaine +DMSO groups, which was absent in saline and cocaine +DAPT groups. Quantification of Evans blue $(\boldsymbol{F})$ and sodium fluorescein $(\boldsymbol{G})$ extravasation into the brains following cocaine injection. All the data are presented as mean $\pm S D, n=5$ per group. ${ }^{*} p<0.05,{ }^{* *} p<0.01$ versus saline group; ${ }^{\#} p<0.05$ versus cocaine-treated group. 
CSL or an empty vector. As shown in Figure 3E, PCR of Flagimmunoprecipitated DNA using primers flanking the CSL consensus site confirmed direct binding of CSL to the PDGF-B promoter.

\section{Notch1 signaling is critical for cocaine-mediated disruption of BBB}

Having determined PDGF-B as a novel target gene of Notch1 signaling and keeping in mind that PDGF-B is a known vascular permeant (Yao et al., 2011a), we next sought to examine whether cocaine-mediated Notch1 signaling played a critical role in mediating increased permeability of endothelial cells. Exposure of HBMEC monolayer to cocaine resulted in increased permeability, which was ameliorated in cells pretreated with DAPT (Fig. $4 A$ ). Intriguingly, Jagged-1 peptide was also capable of enhancing endothelial cell permeability (Fig. 4B), and this effect was ameliorated by PDGF-B-neutralizing antibody (Fig. 4C). These findings thus underscore the role of Notch1 signaling in cocaine-mediated enhancement of endothelial permeability.

\section{In vivo involvement of Notch1 signaling in cocaine-mediated permeability}

To validate cocaine-mediated induction of NICD in vivo, brain homogenates isolated from cocaine versus saline-treated mice were assessed for expression of both NICD and PDGF-B. As shown in Figure $4 D$, cocaine-administered mice demonstrated increased expression of both NICD and PDGF-B in brain tissues compared with saline group. Interestingly, mice pretreated with DAPT demonstrated attenuated expression of both NICD and PDGF-B compared with cocaine-treated animals. DMSO-treated animals, as expected, demonstrated cocaine-mediated induction of NICD and PDGF-B.

Having determined that cocaine treatment enhanced expression of its downstream targets, NICD and PDGF-B, the next step was to carry out functional assays to determine whether mice treated with cocaine demonstrated increased permeability of $\mathrm{BBB}$. We evaluated the extravasation of Evans blue dye into the brain parenchyma, an indicator of disrupted BBB permeability (Armulik et al., 2010; Daneman et al., 2010). In the cocainetreated group, there was increased Evans blue extravasation into the brain parenchyma compared with the saline group, and this effect was ameliorated by in mice pretreated with DAPT, but not DMSO. Quantification of the Evans blue dye in the brain parenchyma demonstrated enhanced levels in cocaine-treated group compared with the DAPT-treated group. As expected, no Evans blue extravasation was observed in saline-treated mice (Fig. $4 E, F)$. To further validate this finding, permeability of lowmolecular-weight sodium fluorescein was also assessed in the brains of cocaine- and saline-treated mice. As demonstrated in Figure $4 G$, cocaine administration resulted in increased vascular permeability compared with the DMSO group, and this effect was ameliorated in mice pretreated with DAPT, lending support to the suggestion that Notch 1 signaling plays a critical role in vascular leakiness.

\section{Discussion}

In summary, we have identified PDGF-B as a novel Notch1 downstream target gene in endothelial cells. While there are reports on the role of Notch1 signaling in neurogenesis (Wang et al., 2004) and synaptic plasticity (Berezovska et al., 1999), our findings suggest yet another function of Notchl signaling - that of mediating increased endothelial permeability via induction of PDGF-B expression. Cocaine has been shown to impair BBB by modulating transcriptional regulation of key cellular functional genes (Fiala et al., 1998). This study highlights yet another gene, PDGF-B that is regulated by cocaine and its downstream Notch1 signaling.

In this study, using both the pharmacological inhibitor of $\gamma$-secretase DAPT and the siRNA-mediated knockdown of NICD, we validated the role of cocaine-mediated activation of Notch in PDGF-B expression. While these knockdown approaches are valuable tools, it must be pointed out that they are not mutually exclusive and need to be used in conjunction to confirm the role of Notch pathway. For example, using DAPT, we did not achieve complete abrogation of PDGF-B (Fig. 2 B), unlike the siRNA NICD-transfected cells (Fig. 2E) that demonstrated a complete knockdown of PDGF-B. Since at the present time there are no reagents available to measure the $\gamma$-secretase activity, it could be speculated that either the incomplete inhibition of PDGF-B by DAPT could be attributed to an incomplete blockade of $\gamma$-secretase or that there must exist a $\gamma$-secretase-independent compensatory pathway upstream of NICD that could be involved in activation of NICD and hence induction of PDGF-B.

This study also addresses an important issue of how drugs of abuse, such as cocaine, can hijack host intracellular signaling pathways to achieve cellular dysfunction. This is the first study to elucidate cocaine-mediated activation of Notch1 signaling. These findings could have ramifications for the role of Notch1 signaling in addiction research in HIV-infected individuals.

\section{References}

Antinori A, Arendt G, Becker JT, Brew BJ, Byrd DA, Cherner M, Clifford DB, Cinque P, Epstein LG, Goodkin K, Gisslen M, Grant I, Heaton RK, Joseph J, Marder K, Marra CM, McArthur JC, Nunn M, Price RW, Pulliam L, et al. (2007) Updated research nosology for HIV-associated neurocognitive disorders. Neurology 69:1789-1799.

Armulik A, Genové G, Mäe M, Nisancioglu MH, Wallgard E, Niaudet C, He L, Norlin J, Lindblom P, Strittmatter K, Johansson BR, Betsholtz C (2010) Pericytes regulate the blood-brain barrier. Nature 468:557-561.

Arumugam TV, Chan SL, Jo DG, Yilmaz G, Tang SC, Cheng A, Gleichmann M, Okun E, Dixit VD, Chigurupati S, Mughal MR, Ouyang X, Miele L, Magnus T, Poosala S, Granger DN, Mattson MP (2006) Gamma secretase-mediated Notch signaling worsens brain damage and functional outcome in ischemic stroke. Nat Med 12:621-623.

Berezovska O, McLean P, Knowles R, Frosh M, Lu FM, Lux SE, Hyman BT (1999) Notch 1 inhibits neurite outgrowth in postmitotic primary neurons. Neuroscience 93:433-439.

Chen L, Swartz KR, Toborek M (2009) Vessel microport technique for applications in cerebrovascular research. J Neurosci Res 87:1718-1727.

Daneman R, Zhou L, Kebede AA, Barres BA (2010) Pericytes are required for blood-brain barrier integrity during embryogenesis. Nature 468:562-566.

Fiala M, Gan XH, Zhang L, House SD, Newton T, Graves MC, Shapshak P, Stins M, Kim KS, Witte M, Chang SL (1998) Cocaine enhances monocyte migration across the blood-brain barrier. Cocaine's connection to AIDS dementia and vasculitis? Adv Exp Med Biol 437:199-205.

Fiala M, Eshleman AJ, Cashman J, Lin J, Lossinsky AS, Suarez V, Yang W, Zhang J, Popik W, Singer E, Chiappelli F, Carro E, Weinand M, Witte M, Arthos J (2005) Cocaine increases human immunodeficiency virus type 1 neuroinvasion through remodeling brain microvascular endothelial cells. J Neurovirol 11:281-291.

Jin S, Hansson EM, Tikka S, Lanner F, Sahlgren C, Farnebo F, Baumann M, Kalimo H, Lendahl U (2008) Notch signaling regulates platelet-derived growth factor receptor-beta expression in vascular smooth muscle cells. Circ Res 102:1483-1491.

Kalasinsky KS, Bosy TZ, Schmunk GA, Ang L, Adams V, Gore SB, Smialek J, Furukawa Y, Guttman M, Kish SJ (2000) Regional distribution of cocaine in postmortem brain of chronic human cocaine users. J Forensic Sci 45:1041-1048.

Kolev V, Mandinova A, Guinea-Viniegra J, Hu B, Lefort K, Lambertini C, 
Neel V, Dummer R, Wagner EF, Dotto GP (2008) EGFR signalling as a negative regulator of Notch1 gene transcription and function in proliferating keratinocytes and cancer. Nat Cell Biol 10:902-911.

MacKenzie F, Duriez P, Wong F, Noseda M, Karsan A (2004) Notch4 inhibits endothelial apoptosis via RBP-Jkappa-dependent and -independent pathways. J Biol Chem 279:11657-11663.

Nair MP, Schwartz SA, Mahajan SD, Tsiao C, Chawda RP, Whitney R, Don Sykes BB, Hewitt R (2004) Drug abuse and neuropathogenesis of HIV infection: role of DC-SIGN and IDO. J Neuroimmunol 157:56-60.

Noseda M, Chang L, McLean G, Grim JE, Clurman BE, Smith LL, Karsan A (2004) Notch activation induces endothelial cell cycle arrest and participates in contact inhibition: role of p21Cip1 repression. Mol Cell Biol 24:8813-8822.

Noseda M, Fu Y, Niessen K, Wong F, Chang L, McLean G, Karsan A (2006) Smooth muscle alpha-actin is a direct target of Notch/CSL. Circ Res 98:1468-1470.

Sacktor N, McDermott MP, Marder K, Schifitto G, Selnes OA, McArthur JC, Stern Y, Albert S, Palumbo D, Kieburtz K, De Marcaida JA, Cohen B, Epstein L (2002) HIV-associated cognitive impairment before and after the advent of combination therapy. J Neurovirol 8:136-142.

Stephens BG, Jentzen JM, Karch S, Mash DC, Wetli CV (2004) Criteria for the interpretation of cocaine levels in human biological samples and their relation to the cause of death. Am J Forensic Med Pathol 25:1-10.

Su EJ, Fredriksson L, Geyer M, Folestad E, Cale J, Andrae J, Gao Y, Pietras K, Mann K, Yepes M, Strickland DK, Betsholtz C, Eriksson U, Lawrence DA (2008) Activation of PDGF-CC by tissue plasminogen activator impairs blood-brain barrier integrity during ischemic stroke. Nat Med 14:731-737.

Van Dyke C, Barash PG, Jatlow P, Byck R (1976) Cocaine: plasma concentrations after intranasal application in man. Science 191:859-861.

Wang Y, Chan SL, Miele L, Yao PJ, Mackes J, Ingram DK, Mattson MP, Furukawa K (2004) Involvement of Notch signaling in hippocampal synaptic plasticity. Proc Natl Acad Sci U S A 101:9458-9462.

Webber MP, Schoenbaum EE, Gourevitch MN, Buono D, Klein RS (1999) A prospective study of HIV disease progression in female and male drug users. AIDS 13:257-262.

Yao H, Peng F, Dhillon N, Callen S, Bokhari S, Stehno-Bittel L, Ahmad SO, Wang JQ, Buch S (2009) Involvement of TRPC channels in CCL2mediated neuroprotection against tat toxicity. J Neurosci 29:1657-1669.

Yao H, Yang Y, Kim KJ, Bethel-Brown C, Gong N, Funa K, Gendelman HE, Su TP, Wang JQ, Buch S (2010) Molecular mechanisms involving sigma receptor-mediated induction of MCP-1: implication for increased monocyte transmigration. Blood 115:4951-4962.

Yao H, Duan M, Buch S (2011a) Cocaine-mediated induction of plateletderived growth factor: implication for increased vascular permeability. Blood 117:2538-2547.

Yao H, Kim K, Duan M, Hayashi T, Guo M, Morgello S, Prat A, Wang J, Su TP, Buch S (2011b) Cocaine hijacks $\sigma$ l receptor to initiate induction of activated leukocyte cell adhesion molecule: implication for increased monocyte adhesion and migration in the CNS. J Neurosci 31:5942-5955.

Zhang L, Looney D, Taub D, Chang SL, Way D, Witte MH, Graves MC, Fiala M (1998) Cocaine opens the blood-brain barrier to HIV-1 invasion. J Neurovirol 4:619-626. 